\title{
Mukaiyama diastereoismers pattern by computational studies
}

\author{
Santos, W. W. C.*; João B. L. Martins; Murta, M. M.; Resck, I. S. and dos Santos, M. L. \\ Instituto de Química, Universidade de Brasília, Brasilia-DF, Brazil \\ *e-mail corresponding author: wendellcruz@unb.br
}

Keywords: Macrocyclization, diastereoisomers, zearalenone analogues

\section{INTRODUCTION}

Ring-closing reaction is a critical step in the synthesis of macrocyclic compounds due to entropic and enthalpic factors, associated with transition states direct cyclization in generally is not possible without activation. ${ }^{1}$ Our efforts to obtain zearalenone analogues from anacardic acid, have led us to explore some classical macrocyclization methods.

\section{RESULTS AND DISCUSSION}

As outlined in our synthetic approach, the advanced intermediate 1 was treated under Mukaiyama's protocol (carboxyl activation), resulting the group of stereoisomer 2 (42\% yield). Alcohol activation by Mitsunobu method yielded $66 \%$ of 2 (Figure 1).

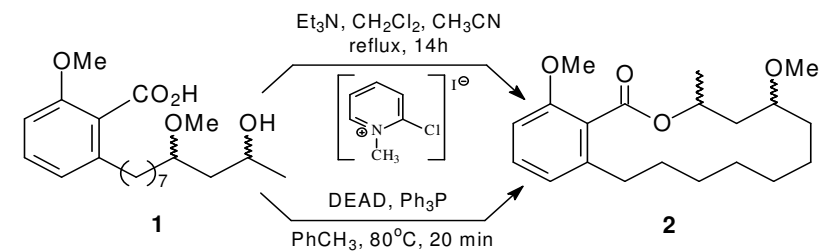

Figure 1. Macrolactonization protocols.

According to ${ }^{1} \mathrm{H}$ NMR spectra data, in the Mitsunobu's product was observed the expected inversion of ratio comparing to the precursors, whereas the Mukaiyama's product exhibited a discriminatory diastereoisomeric pattern, around 2 parts to 1 (Figure 2).

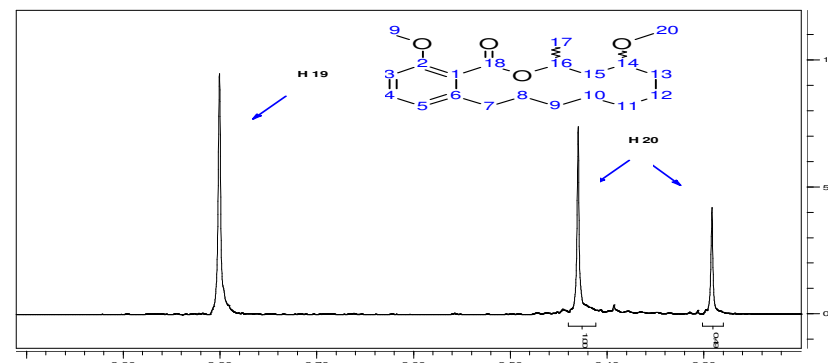

Figure 2. ${ }^{1} \mathrm{H}$ NMR $(300 \mathrm{MHz})$ of the Mukaiyama product.

In order to rationalize these results and determining the favourable diastereoisomer groups from Mukaiyama's protocol, a conformational study on the products was performed by two distinct methods $(\mathrm{MM}+$ force field in HyperChem 5.1 program to windows and MM2 force field in CAChe program). As shown in Table 1, the difference of energy $14^{\text {th }}$ Brazilian Meeting on Organic Synthesis - 14 $4^{\text {th }}$ BMOS - September 01-05, 2011-Brasilia, Brazil between diastereoisomers was comparable in both methods.

\begin{tabular}{|c|c|c|c|}
\hline $\begin{array}{c}\text { Force } \\
\text { field }\end{array}$ & $\begin{array}{c}\text { Energy } \\
\left(\mathrm{kJ} . m o l^{-1}\right) \\
\text { trans isomer }\end{array}$ & $\begin{array}{c}\text { Energy } \\
\left(\mathrm{kJ}^{-1} \mathrm{~mol}^{-1}\right) \\
\text { cis isomer }\end{array}$ & $\begin{array}{c}\Delta \mathrm{E} \\
\left(\mathrm{kJ}_{\mathrm{mol}}{ }^{-1}\right)\end{array}$ \\
\hline $\mathrm{MM}+$ & 158.0225 & 160.5296 & 2.5070 \\
\hline $\mathrm{MM} 2$ & 91.3735 & 94.1770 & 2.8035 \\
\hline
\end{tabular}

Table 1. Energy profile of conformational study.

The correlation between the number of particles in the discrete states using Boltzmann distribution law, at $40{ }^{\circ} \mathrm{C}$ and $\Delta \mathrm{E}$ equal to $2.8035 \mathrm{~kJ} \cdot \mathrm{mol}^{-1}$, gave the ratio of 3 parts to 1 between trans and cis isomers. The ${ }^{13} \mathrm{C}$ NMR chemical shifts assignments are in accordance with the structure of more stable trans isomer (Figure 3).
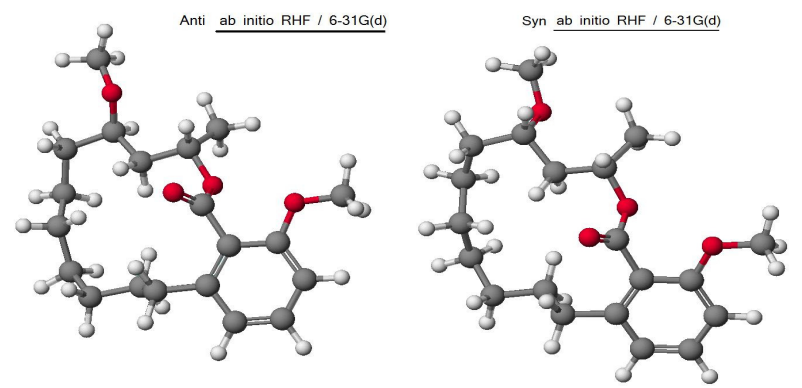

Figure 3. Stable conformations of trans and cis isomers.

\section{CONCLUSION}

A mixture of macrocyclic diastereoisomers was accessible by both applied macrocyclization methods. The conformational study on Mukaiyama's product suggests that the trans isomer is more favorable, corroborating the spectroscopy properties. However the estimated grade of stereoselectivity must be based on relative energy of competitive transition states, these computational data can provide qualitative information about ratio of the products, since the reaction was performed under thermodynamic control.

\section{ACKNOWLEDGEMENTS}

Financial support: CNPq (fellowship funds to WWCS), FUB, FINEP (CT-INFRA 970/2001).

\section{REFERENCES}

${ }^{1}$ Parentely, A.; Moreau, X, Campagne, J.-M. Chem. Rev. 2006, 106, 911. 